\title{
The intake of carotenoids in an older Australian population: The Blue Mountains Eye Study
}

\author{
Fiona Manzi ${ }^{1,2}$, Victoria Flood ${ }^{1}$, Karen Webb ${ }^{1,3}$ and Paul Mitchell ${ }^{2, *}$ \\ 'University of Sydney Department of Public Health \& Community Medicine, Westmead Hospital, Westmead, \\ Australia: ${ }^{2}$ University of Sydney Department of Ophthalmology, Eye Clinic, Westmead Hospital, Westmead, NSW \\ 2145, Australia: ${ }^{3}$ University of Sydney Department of Biochemistry, Westmead Hospital, Westmead, Australia
}

Submitted 8 May 2001: Accepted 20 August 2001

\begin{abstract}
Objective: To describe the distribution of carotenoid intakes and important food sources of carotenoids in the diet of a representative population of older Australians. Design: Population-based cohort study.

Setting: Two post-code areas in the Blue Mountains, west of Sydney, Australia.

Subjects: We studied 2012 (86\%) of the 2334 participants aged 55+ years attending the 5-year follow-up of the cross-sectional Blue Mountains Eye Study (BMES), who completed a detailed semi-quantitative food-frequency questionnaire. The intakes for five carotenoids were studied: $\alpha$-carotene, $\beta$-carotene, $\beta$-cryptoxanthin, lutein and zeaxanthin combined, and lycopene.

Results: The mean intake per day for each carotenoid was: $\alpha$-carotene, $2675 \mu \mathrm{g} ; \beta$ carotene equivalents, $7301 \mu \mathrm{g} ; \beta$-cryptoxanthin, $299 \mu \mathrm{g}$; lutein and zeaxanthin, $914 \mu \mathrm{g}$; lycopene, $3741 \mu \mathrm{g}$; retinol, $653 \mu \mathrm{g}$; total vitamin A, $1872 \mu \mathrm{g}$ retinol equivalents. $\beta$-Carotene equivalents contribute a substantial proportion of total vitamin A intake (65\%) in this population. Women had slightly higher intakes than men for $\alpha$-carotene, $\beta$-carotene equivalents, and lutein and zeaxanthin $(P<0.05)$. Carrots and pumpkin were the main contributors to $\alpha$-carotene and $\beta$-carotene equivalent intakes. Orange juice, oranges and papaw were the main contributors to $\beta$-cryptoxanthin intake. Broccoli, green beans and oranges contributed substantially to lutein and zeaxanthin intake. The main contributors to lycopene intake were tomatoes and bolognaise sauce.

Conclusions: Vitamin A intake in this population is high relative to the Australian Recommended Dietary Intake. Carotenoid intakes, particularly $\beta$-carotene, make a substantial contribution, particularly from fruit and vegetables. This study provides important information as a basis for examining associations between dietary carotenoid intake and eye disease in the BMES.
\end{abstract}

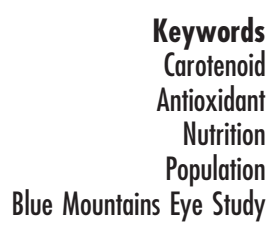

Keywords

Nutrition

Population

Blue Mountains Eye Study
Carotenoids are widely distributed in nature and contribute to the colour in plants and their fruits ${ }^{1}$. There are over 600 carotenoids known to exist. The predominant carotenoids in human plasma are $\beta$ carotene, lycopene, lutein, zeaxanthin, $\beta$-cryptoxanthin and $\alpha$-carotene ${ }^{2}$.

Carotenoids are best known for their role as a precursor to retinol, or vitamin A. $\beta$-Carotene is the most important pro-vitamin A carotenoid ${ }^{1}$. Carotenoids may also be protective against oxidative stress and some forms of chronic disease ${ }^{3}$. The singlet-oxygen-quenching ability of $\beta$-carotene was first described by Foote, identifying $\beta$-carotene as a catalyst that deactivates the potentially harmful singlet oxygen ${ }^{4}$. Since then, other carotenoids have been identified with this antioxidant property $^{3,5}$.
The extent to which dietary carotenoid intake is associated with chronic disease in humans is still unclear. The current state of research into carotenoids is not yet sufficiently strong to support any recommendations for dietary carotenoid intake, as indicated in the Report by the Panel on Dietary Antioxidants and Related Compounds ${ }^{6}$.

Some recent studies have assessed associations between carotenoid intake and disease risk in older populations. The Beaver Dam Eye Study (USA) investigated the relationship between diet and supplementary antioxidant nutrient intake and the incidence of nuclear cataract in an older population. The study found that persons with intakes in the highest quintile for lutein 10 years before baseline were half as likely to have an incident cataract as persons in the lowest quintile of intake (rate ratio (RR) 0.5 , 
95\% confidence interval (CI) $0.3-0.8)^{7}$. Two studies investigated the association between dietary carotenoid intake and the incidence of cataract extraction in men and women. These reports suggested that lutein and zeaxanthin may decrease the risk of cataract requiring surgery (RR (95\% CI) women 0.78 (0.63-0.95), men 0.81 (0.651.01) $)^{8,9}$. Another study in an older population found that lutein-containing foods may reduce the risk of developing colon cancer ${ }^{10}$. Two other studies showed that certain dietary carotenoids could reduce risk of ischaemic stroke and oesophageal cancer ${ }^{11,12}$.

Most food composition tables do not provide individual carotenoid values for foods. The studies mentioned have used a carotenoid database developed by the United States Department of Agriculture (USDA) to analyse the carotenoid intakes in their study populations. This database includes carotenoid values from fruits, vegetables and multicomponent foods containing fruits and vegetables for $\alpha$-carotene, $\beta$-carotene, $\beta$-cryptoxanthin, lutein and zeaxanthin combined, and lycopene ${ }^{13,14}$.

There have been no large population-based reports of carotenoid intake in older Australians. The Blue Mountains Eye Study (BMES) provided the opportunity to conduct a secondary analysis on the dietary data to assess carotenoid intakes. We aimed in this study to describe the distribution and important food sources of dietary carotenoid intake in a representative population of older Australians. A further aim was to compare these findings with other published data using similar methods of dietary data collection and analysis $^{7-9,15}$.

\section{Methods}

\section{Study population}

The Blue Mountains Eye Study (BMES) is a populationbased cohort study of vision and common eye diseases among free-living older residents, living within two postcode areas of the Blue Mountains region, west of Sydney. The population is representative of the state of New South Wales for income and socio-economic status ${ }^{16}$. This project was approved by the Western Sydney Area Human Research Ethics Committee and written, informed consent was obtained from all participants.

The BMES population was examined during the period 1992-4, and included 3654 residents aged 49 years or older. All participants were invited to attend 5-year follow-up examinations (BMES2) during 1997-9. BMES2 included 2334 participants aged 55 years or older, with a $75.0 \%$ response, after excluding deaths during the intervening period. The BMES2 dataset was used in this study, of whom 2136 participants (92\% of those examined) completed detailed food-frequency questionnaires (FFQs).

\section{Collection of dietary data}

Dietary intakes were measured in the BMES2 study population by a self-administered, semi-quantitative FFQ modified for Australian diet and vernacular from an earlier FFQ of Willett et al. ${ }^{17}$. A nine-category frequency scale was used to indicate usual frequency of consumption for 145 food items during the past year. The FFQ was produced in large print for easier reading by older, potentially visually impaired participants and took around 45 minutes to complete $^{18}$.

The FFQ was validated against three 4-day weighed food records, collected over one year to account for seasonal variation, in a randomly selected sub-sample of the BMES cohort $(n=79)^{18}$. The FFQ was found to show moderate agreement for antioxidant vitamins, yielding correlation coefficients between 0.3 and 0.6 ( $\beta$-carotene $r=0.46)^{18}$. Retinol showed less agreement $(r=0.29)$. This poor agreement for retinol appeared to be due in part to the overestimation of the frequency and quantity of meat consumed as measured by the FFQ ${ }^{18}$.

FFQ data were checked for outliers and data-entry errors using methods described previously ${ }^{14}$. Subjects with between 13 and 25 missing items were checked for data-entry errors and corrected when identified. FFQs were excluded when more than 12 FFQ items remained blank $(n=101)$. Subjects with calculated daily energy intakes $<2500 \mathrm{~kJ} \mathrm{day}^{-1}$ or $>18000 \mathrm{~kJ} \mathrm{day}^{-1}$ were excluded from analyses $(n=17)$. The distribution for each nutrient was checked and values in the upper and lower $2 \%$ of values were also checked. FFQs with implausible dietary intakes for retinol $(n=2)$ and carotenoids $(n=4)$ were excluded, leaving 2012 cleaned FFQs (86\% of those examined).

Dietary intakes were analysed using a purpose-built software package, which combined the Australian Food Composition Database (NUTTAB95) ${ }^{19}$ and the USDA-NCI Carotenoid Food Composition Database ${ }^{13}$, modified to include foods itemised in the FFQ and NUTTAB95. The USDA Carotenoid Food Composition Database includes values for five carotenoids in 120 separate food items including fruits and vegetables and multicomponent foods containing fruits and vegetables ${ }^{13}$. Lutein and zeaxanthin values are reported together in the USDA database. This is because separation of lutein and zeaxanthin in food analysis techniques is difficult ${ }^{14}$.

The $\beta$-carotene values were analysed using both the NUTTAB95 and USDA databases. NUTTAB95, which reports $\beta$-carotene equivalents, is more comprehensive for Australian foods. Strict $\beta$-carotene values, for comparison with other studies using the USDA database, were calculated from the $\beta$-carotene equivalent values, using the following formula:

$$
\begin{aligned}
& \mu \mathrm{g} \beta \text {-carotene equivalents } \\
& =\mu \mathrm{g} \beta \text {-carotene }+\mu \mathrm{g} \alpha \text {-carotene } / 2 \\
& \quad+\mu \mathrm{g} \beta \text {-cryptoxanthin } / 2 .
\end{aligned}
$$

Retinol and retinol equivalent (RE) values were also 
analysed using data from NUTTAB95. Retinol equivalents were calculated by NUTTAB95, using the equation:

$\mu \mathrm{g}$ retinol equivalents ( $\mu \mathrm{g} \mathrm{RE}$ ) $=\mu \mathrm{g}$ retinol $+\beta$-carotene equivalents $/ 6$.

\section{Statistical analysis}

Analyses were conducted using the statistical package SPSS (version 7.5) ${ }^{20}$. Carotenoid intake distributions in age- and sex-stratified analyses were obtained. Student's $t$ test and one-way analysis of variance (ANOVA) were used to determine differences in carotenoid intake between women and men and for age categories; $P$-values of $<0.05$ were considered significant. Four age categories were used initially $(<65,65-74,75-84,>84)$ and, subsequently, subjects were split into two broader age categories based on the median age $(<69, \geq 69)$. Individual food items were ranked according to contribution (per capita) to carotenoid intake for both men and women.

\section{Results}

Table 1 presents mean intakes of carotenoids for women and men by age categories. For the carotenoids $\alpha$-carotene $(P=0.003), \beta$-carotene equivalents, lutein and zeaxanthin (each $P<0.001$ ), women had slightly higher intakes than men. Men had a slightly higher intake for retinol $(P=$ $0.008)$ than women. There were no significant differences for total vitamin A $(P=0.270), \beta$-cryptoxanthin $(P=$ $0.107)$ and lycopene $(P=0.061)$ between women and men.

Women aged $\geq 69$ years had slightly higher intakes for $\alpha$-carotene $(P=0.002), \quad \beta$-carotene equivalents $(P=$ $0.007)$ and $\beta$-cryptoxanthin $(P=0.017)$, when compared with younger participants. Women aged $<69$ years had slightly higher intakes of lycopene $(P<0.001)$ than those in the older category. Men aged $\geq 69$ years had slightly higher intakes for $\alpha$-carotene $(P=0.002), \beta$-carotene equivalents $(P=0.001), \beta$-cryptoxanthin $(P=0.002)$ and total vitamin A $(P=0.046)$ than those in the younger age category. Men aged $<69$ years had slightly higher intakes of lycopene $(P=0.003)$ than older participants. Trends were similar for total persons between the age groups.

The mean intake for total vitamin A (RE) in this population was $1872 \mu \mathrm{gREday}{ }^{-1}$ (range 119$6963 \mu \mathrm{g} \mathrm{RE} \mathrm{day}^{-1}$ ). The Australian Recommended Dietary Intake (RDI) ${ }^{21}$ for total vitamin A is $750 \mu \mathrm{g} \mathrm{RE} \mathrm{day}^{-1}$. Table 1 shows that, for both women and men, mean intakes were well above this recommended level. A small percentage $(7.8 \%)$ of the population had intakes below the RDI. The mean intake of $\beta$-carotene equivalents was $7301 \mu$ g day $^{-1}$. This represents $65 \%$ of the total vitamin A intake for the population.

Table 2 presents data from comparable populationbased studies. The mean intakes for $\beta$-carotene in the 


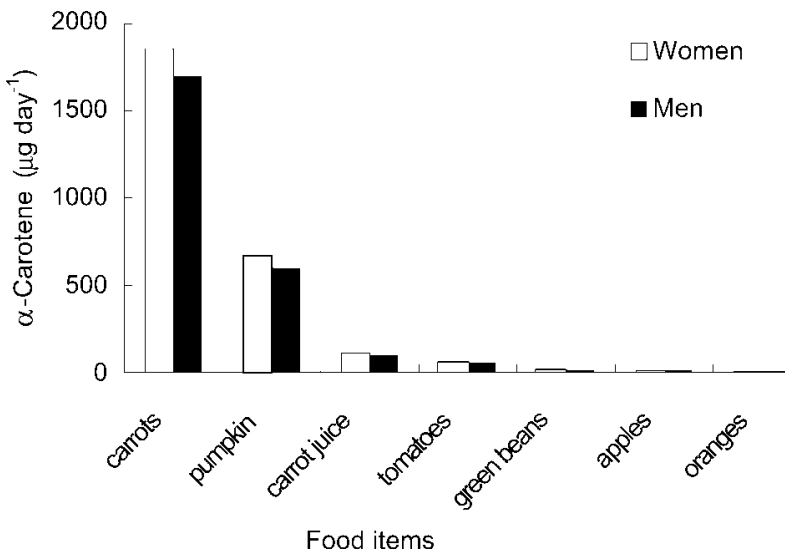

Fig. 1 The main contributors to mean intakes of $\alpha$-carotene $\left(\mu \mathrm{g} \mathrm{day}^{-1}\right)$ in women and men

BMES population were similar to intakes reported from the Health Professionals Study ${ }^{8}$ and a colon cancer study ${ }^{10}$ but higher than intakes reported from the Nurses Health Study ${ }^{9}$ and the study by Forman ${ }^{15}$. Mean or median intakes for $\alpha$-carotene and $\beta$-cryptoxanthin were higher, while lutein, zeaxanthin and lycopene intakes were lower in the BMES population than reported from most other studies.

Figures 1-6 present the important food sources of each carotenoid and for total vitamin A intake. Carrots and pumpkin were the most important food sources of $\alpha$ carotene and $\beta$-carotene for this population (Figs 1 and 2 ). Important food sources of $\beta$-cryptoxanthin were fruits, in particular orange juice, oranges and papaw (Fig. 3). Green vegetables such as broccoli, green beans, Brussels sprouts and oranges (fresh and juice) were important contributors to lutein and zeaxanthin (Fig. 4). The most important sources of lycopene (Fig. 5) in this population were tomatoes and tomato products.

Figure 6 shows that carrots, being rich in $\beta$-carotene, were the most important source of total vitamin A intake, followed by liver, a rich source of retinol.

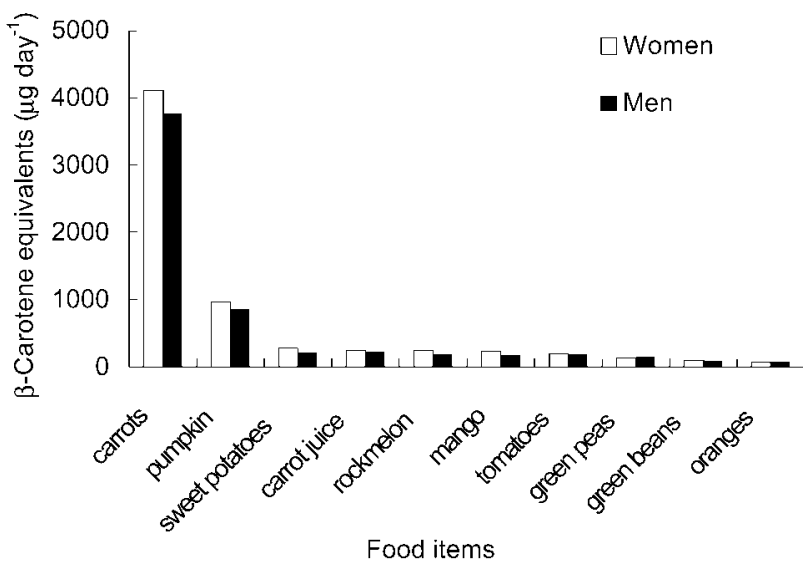

Fig. 2 The main contributors to mean intakes of $\beta$-carotene $\left(\mu \mathrm{g} \mathrm{day}^{-1}\right)$ in women and men 


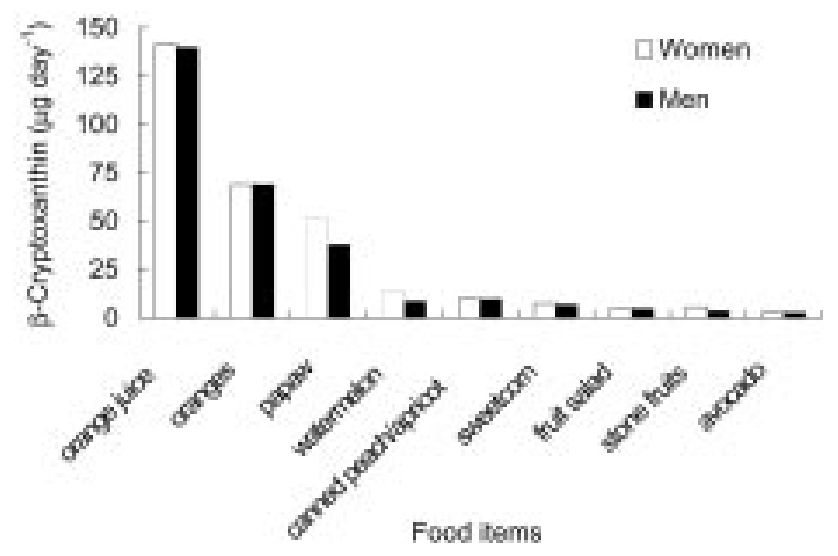

Fig. 3 The main contributors to mean intakes of $\beta$-cryptoxanthin $\left(\mu \mathrm{g} \mathrm{day}^{-1}\right)$ in women and men

\section{Discussion}

The average daily intake for total vitamin A among the BMES sample was substantially greater than the current RDI in this older Australian population. $\beta$-Carotene equivalents were the major contributor (65\%) to total vitamin A intake, and were thus the most important source of vitamin $A$ in this population. Intakes of $\beta$-carotene equivalents in the BMES were substantially higher than those reported in the Australian National Nutrition Survey for men and women aged 65 years and older (men $3918 \mu \mathrm{g} \mathrm{day}^{-1}$, women $\left.3494 \mu \mathrm{g} \mathrm{day}^{-1}\right)^{22}$.

There are no current RDIs for carotenoids. Thus the adequacy of intakes of particular carotenoids in this study cannot be assessed. Yet, comparison of our results with those of other studies provides a gauge of how our population ranks with respect to intakes of selected carotenoids.

Our findings of higher intakes of $\alpha$-carotene, $\beta$ carotene and $\beta$-cryptoxanthin than other published studies, and the substantially high vitamin A intakes reported here, may be due to an overestimation of

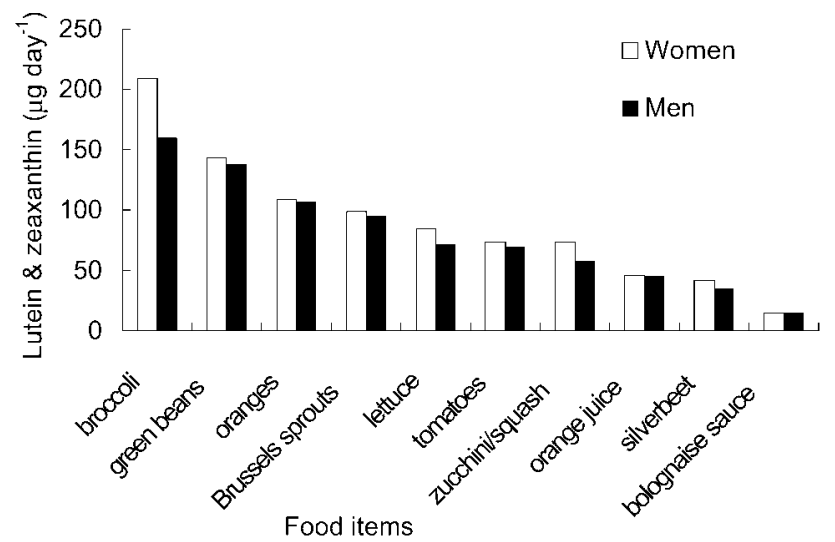

Fig. 4 The main contributors to mean intakes of lutein and zeaxanthin $\left(\mu \mathrm{g} \mathrm{day}^{-1}\right)$ in women and men

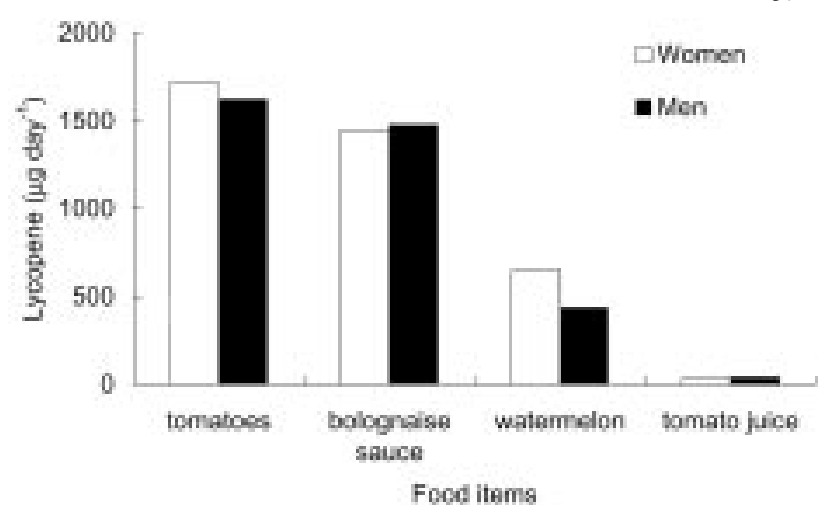

Fig. 5 The main contributors to mean intakes of lycopene $\left(\mu \mathrm{g} \mathrm{day}^{-1}\right)$ in women and men

carotenoid and retinol intakes by our FFQ. It is known that the FFQ instrument tends to overestimate nutrient consumption of individuals. Overestimation will tend to be greater with a large number of items included, as in our questionnaire ${ }^{23}$. Some studies have found that intakes estimated from FFQs were significantly higher than those from weighed records for nutrients derived primarily from fruits and vegetables ${ }^{24,25}$. Our FFQ included 145 items comprising a long list of fruits and vegetables. However, the fact that some of the measured carotenoid intakes were lower in our population than in other published studies suggests that at least some of the differences were likely due to real differences in food consumption between populations, for example possibly lower consumption of spinach and tomatoes in our population, but higher consumption of pumpkin.

The food composition database used to derive our estimates of carotenoid intakes is the most comprehensive carotenoid database available. Yet for some carotenoids, such as lutein and zeaxanthin, food composition data are limited. For some foods, values for all five carotenoids were not available, so our results might have underestimated carotenoid intakes because of incomplete food composition data. Furthermore, not all of the items on our

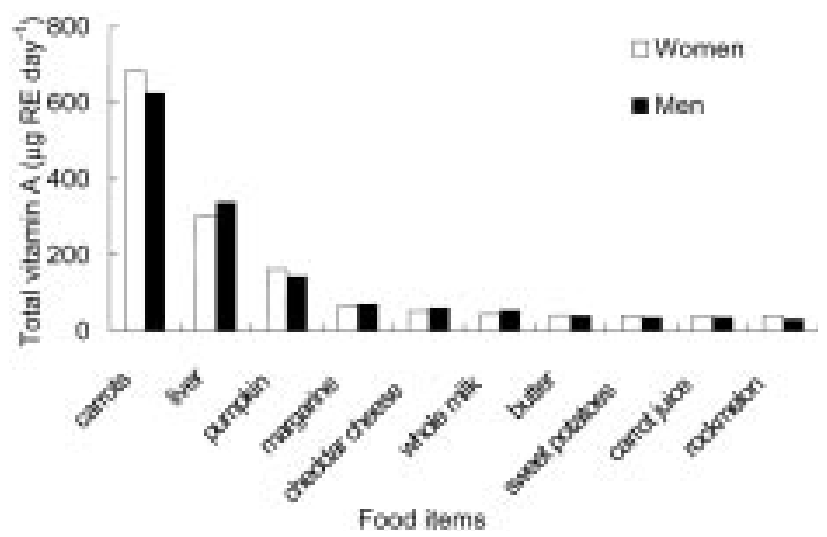

Fig. 6 The main contributors to mean intakes of total vitamin A $\left(\mu \mathrm{gRE} \mathrm{day}^{-1}\right)$ in women and men 
FFQ could be exactly matched with one of the 120 items in the USDA carotenoid database. For example, our questionnaire lists cooked, mashed or baked pumpkin, and silverbeet, and the closest matches on the USDA database were canned pumpkin, and spinach. Differences such as these in food preparation, food varieties and possible food colouring added to US canned products may limit the accuracy of our estimates for the Australian food supply and our population, in particular.

An analysis of the foods consumed by the Blue Mountains Eye Study population does provide further information about the important sources of carotenoids in older populations. Some foods that are rich sources of carotenoids provide a high contribution to the mean intake, but are only consumed by a small proportion of the population. For example, carrot juice was a high contributor to the mean intakes of $\beta$-carotene, $\alpha$-carotene and total vitamin A, but is only consumed by $23 \%$ of women and $17 \%$ of men.

The findings of this study provide a basis for conducting further analysis of relationships between particular carotenoids and eye diseases, including age-related macular degeneration and cataract, in an older Australian population. It also confirms that the most important sources of these nutrients are fruits and vegetables. The investigation of important sources of carotenoids in the diet of this older population may prove beneficial as a basis for public health interventions aimed at increasing intakes of certain carotenoids, should they be confirmed as protective for eye diseases and other chronic diseases.

\section{References}

1 Stahl W, Sies H, Sundquist AR. Role of carotenoids in antioxidant defence. In: Blomhoff R, ed. Vitamin A in Health and Disease. New York: Marcel Dekker, 1994.

2 Krinsky NI, Mayne ST. Current views on carotenoids: biology, epidemiology and trials. In: Livrea MA, ed. Vitamin $A$ and Retinoids: An Update of Biological Aspects and Clinical Applications. Boston, MA: Birkhuser Verlag, 2000.

3 Mayne ST. $\beta$-Carotene, carotenoids, and disease prevention in humans. FASEB J 1996; 10: 690-701.

4 Foote CS, Denny RW. Chemistry of singlet oxygen VIII. Quenching by $\beta$-carotene. J. Am. Chem. Soc. 1968; 271(26): 490-8.

5 Krinsky NI. Antioxidant functions of carotenoids. Free Radical Biol. Med. 1989; 7: 617-35.

6 Rock CL. Dietary Reference Intakes, antioxidants, and betacarotene. J Am. Diet. Assoc. 1998; 98(12): 1410-1.

7 Lyle BJ, Mares-Perlman JA, Klein BEK, Klein R, Greger JL. Antioxidant intake and risk of incident age-related nuclear cataracts in the Beaver Dam Eye Study. Am. J. Epidemiol. 1999; 149(9): 801-9.

8 Brown L, Rimm EB, Seddon JM, Giovannucci EL, ChasanTaber L, Spiegelman D, Willett WC, Hankinson SE. A prospective study of carotenoid intake and risk of cataract extraction in US men. Am. J. Clin. Nutr. 1999; 70: 517-24.
9 Chasan-Taber L, Willett WC, Seddon JM, Stampfer MJ, Rosner B, Colditz GA, Speizer FE, Hankinson SE. A prospective study of carotenoid and vitamin A intakes and risk of cataract extraction in US women. Am.J. Clin. Nutr. 1999; 70: 509-16.

10 Slattery ML, Benson J, Curtin K, Ma K, Schaeffer D, Potter JD. Carotenoids and colon cancer. Am. J. Clin. Nutr. 2000; 71 : 575-82.

11 Ascherio A, Rimm EB, Hernan MA, Giovannucci E, Kawachi I, Stampfer MJ, Willett WC. Relation of consumption of vitamin E, vitamin C, and carotenoids to risk for stroke among men in the United States. Ann. Intern. Med. 1999; 130(12): 963-70.

12 Franceschi S, Bidoli E, Negri E, Zambon P, Talamini R, Ruol A, Parpinel M, Levi F, Simonato L, La Vecchia C. Role of macronutrients, vitamins and minerals in the aetiology of squamous-cell carcinoma of the oesophagus. Int. J. Cancer 2000; 86(5): 626-31.

13 Chug-Ahuja JK, Holden JM, Forman MR, Reed Mangels A, Beecher GR, Lanza E. The development and application of a carotenoid database for fruits, vegetables and, selected multi-component foods. J. Am. Diet. Assoc. 1993; 93(3): $318-23$.

14 Reed Mangels A, Holden JM, Beecher GR, Forman MR, Lanza E. Carotenoid content of fruits and vegetables: an evaluation of analytic data. J Am. Diet. Assoc. 1993; 93(3): 284-96.

15 Forman MR, Lanza E, Yong LC, Holden JM, Graubard BI, Beecher GR, Melitz M, Brown ED, Smith JC. The correlation between two dietary assessments of carotenoid intake and plasma carotenoid concentrations: application of a carotenoid food-composition database. Am. J. Clin. Nutr. 1993; 58: $519-24$.

16 Webb KL, Schofield WN, Lazarus R, Smith W, Mitchell P, Leeder SR. Prevalence and socio-demographic predictors of dietary goal attainment in an older population. Aust. NZ J. Public Health 1999; 23(6): 578-84.

17 Willett W, Sampson L, Browne ML, Stampfer MJ, Rosner B, Hennekens $\mathrm{CH}$, Speizer FE. The use of a self-administered questionnaire to assess diet four years in the past. $\mathrm{Am}$. J. Epidemiol. 1988; 127(1): 188-99.

18 Smith W, Mitchell P, Reay EM, Webb K, Harvey PWJ. Validity and reproducibility of a self-administered food frequency questionnaire in older people. Aust. NZ J. Public Health 1998; 22(4): 456-63.

19 Department of Community Services and Health. Nuttab95 Nutrient Database for Use in Australia. Canberra: Australian Government Publishing Service, 1995.

20 SPSS, Inc. SPSS for Windows: Release 7.5.1. Chicago, IL: SPSS, Inc., 1989-1996.

21 National Health and Medical Research Council Recommended Dietary Intakes for Use in Australia. Canberra: Australian Government Publishing Service, 1991.

22 McLennan W, Podger A. National Nutrition Survey; Nutrient Intakes and Physical Measurements, Australia 1995. Canberra: Australian Bureau of Statistics, 1998.

23 Liu K. Statistical issues related to semi-quantitative food frequency questionnaires. Am. J. Clin. Nutr. 1994; 59(Suppl.): 262S-5S.

24 Wheeler C, Rutishauser IHE, O'Dea K. Comparison of nutrient intake data from two food frequency questionnaires and weighed records. Aust. J. Nutr. Diet 1995; 52: 140-8.

25 Feskanich D, Rimm EB, Giovannucci EL, Colditz GA, Stampfer MJ, Litin LB, Willett WC. Reproducibility and validity of food intake measurements from a semiquantitative food frequency questionnaire. J. Am. Diet. Assoc. 1993; 93: 790-6. 